\title{
PEMANFAATAN WEBSITE SEBAGAI SARANA MANAGING DATA DALAM SUATU ORGANISASI (STUDI KASUS: PERTEMUAN ILMIAH NASIONAL (PIN) PERHIMPUNAN DOKTER SPESIALIS SARAF INDONESIA (PERDOSSI) 2013 MEDAN)
}

\author{
Rachmat Aulia \\ Teknik Informatika Sekolah tinggi Teknik Harapan Medan \\ Jl.HM Joni No 70 A Medan 20152 Indonesia \\ jackm4t@gmail.com
}

\begin{abstract}
Abstrak-Sistem informasi merupakan sebuah sistem yang dirancang untuk memproses datadata sehingga dapat menghasilkan informasi yang berharga untuk diinformasikan kepada umum. Kategori dari sistem informasi beraneka ragam salah satunya adalah pengelolaan data (managing data) online. Sistem seperti pengelolaan data secara online sangat diperlukan di beberapa organisasi atau perusahaan. Hal ini dapat membantu dan memudahkan panitia dalam melakukan perkerjaan. Rancangan aplikasi managing data online yang terdapat pada PIN (pertemuan ilmiah nasional) 2013 Medan menerapkan beberapa teknologi seperti verifikasi dan filterisasi data, identifikasi pembayaran, error handling, dan encryption login. Alasan mengapa banyak teknologi yang diterapakan dalam sistem PIN 2013 Medan adalah meminimalkan kesalahan dan kerugian yang ditimbulkan baik dari panitia maupun peserta sehingga kedua belah pihak saling menguntungkan.
\end{abstract}

Keywords - Sistem Informasi, Managing Data Online, Pengelolaan Data, Website Organisasi.

\section{PENDAHULUAN}

Perkembangan data dewasa ini mengharuskan perusahaan atau organisasi mengelola data dalam jumlah besar dengan bantuan sebuah sistem yang terkomputerisasi. Hal ini bertujuan untuk dapat membantu pekerja dalam suatu perusahaan atau organisasi supaya mengetahui kriteria data apa yang di-input dan kemudian diproses untuk ditampilkan hasilnya (informasi) ke khalayak umum. Transparansi ini akan menyebabkan kepercayaan (trusted) bagi banyak orang sehingga mendorong mereka dapat bergabung dengan organisasi / perusahaan yang mereka inginkan.

Penyajian data secara digital dapat dirancang dengan membuat suatu website yang dapat digunakan untuk pengelolaan data bagi organisasi. Dengan hadirnya website pada suatu organisasi membuat managing data menjadi mudah dengan alur atau sistematika yang telah ditentukan sehingga dapat memfilterisasi data yang masuk ke dalam sebuah sistem. Teknik filterisasi berperan dalam meng-input $\neg$ kan data agar dapat menyeleksi data mana yang layak dimasukkan atau tidak. Hal ini berguna agar tidak menimbulkan berbagai macam kerugian pada organisasi dalam mengelola data tidak layak yang terinput.

Perancangan website sebagai sarana managing data tidak hanya harus menerapkan konsep filterisasi data namun juga harus mendukung securitas yang reliable. Securitas berfungsi untuk meminimalkan aksi-aksi dari pihak illegal (tidak resmi) untuk mengacaukan atau merobohkan sistem yang telah dibangun. Website yang dibangun untuk organisasi PERDOSSI ini telah menerapakan konsep securitas seperti SQL Injection (memanfaatkan kelemahan dari suatu website yang mengijinkan user meng-input-kan data tertentu tanpa melakukan filter terhadap malicious character (Rawuh, S. 2013)) dan penggunaan fungsi enkripsi yaitu MD5 untuk mengenkripsi akun password suatu administrator yang digunakan untuk login ke sistem agar dapat melakukan kegiatan managing data tersebut

Managing data yang dilakukan pada website yang digunakan oleh organisasi PERDOSSI ini adalah kegiatan yang memiliki pengertian sama dengan manipulasi data yaitu: memasukkan data (insert data), memperbaharui data (update data), menghapus data (delete data) dan pencarian data (searching data). Keempat fungsi yang termasuk dalam manipulasi data tersebut mempermudah organisasi data yang terdapat dalam website PERDOSSI seperti kegiatan registrasi data, menerbitkan informasi terbaru, konfirmasi pembayaran, mengesahkan (approve) calon perserta menjadi perserta absah (valid) dan merubah serta menambah contents untuk disajikan dalam website tersebut.

PIN merupakan suatu kegiatan pertemuan ilmiah tingkat nasional yang dimiliki oleh organisasi PERDOSSI (perhimpunan dokter spesialis saraf Indonesia), diadakan annually di berbagai tempat di Indonesia. Pembentukan organisasi ini terjadi pada tanggal 15-16 September 1970 di suatu peristirahatan di Gombel, Semarang. Pada kesempatan itu berlangsung pertemuan empat puluh satu (41) dokter 
ahli (Neurologi, Psikiatri dan Neurochirurgi) dari berbagai daerah yang dipimpin oleh Prof.DR. Mahar Mardjono, dengan maksud untuk memperluas perhimpunan yang sebelumnya hanya meliputi lingkungan FKUI / RSUP Jakarta saja (Perdossi, 2009).

\section{A. Batasan Masalah}

Adapun batasan masalah pada penelitian ini adalah sebagai berikut :

1. Sistem yang dirancang ini merupakan sistem registrasi online yang ditujukan untuk para peserta yang ingin mendaftar untuk mengikuti acara PIN Perdossi 2013 di Medan

2. Sistem yang dirancang ini hanya dapat melakukan pengelolaan data berupa penambahan, pembaharuan, penghapusan dan pencarian data yang biasa dikenal sebagai data manipulation

3. Perangkat lunak yang digunakan bersifat open source seperti: web server Apache versi 2.2, PHP versi 5.0 dan MySQL versi 5.6

4. Panitia Perdossi Medan dapat mengetahui siapakah perserta yang telah melakukan pembayaran dengan cara memasukkan token yang telah diperoleh dari pihak bank untuk login ke dalam internet banking

5. Konfirmasi pembayaran dapat dilakukan dengan mengisi sebuah form yang telah disediakan di website dengan cara men-download-nya yang selanjutnya dikirim ke e-mail panitia Perdossi cabang Medan.

\section{B. Tujuan Penelitian}

Penelitian ini bertujuan untuk membantu panitia Perdossi daerah kota Medan dalam memantau dan memverifikasi pengelolaan data yang telah terorganisir atau sistematis. Berdasarkan tujuan tersebut sehingga diperoleh manfaatnya, antara lain:

1. Memudahkan Panitia dalam mengelola data pada skala besar

2. Mengaplikasikan teknik filterisasi data yang benar sehingga dapat meminimalkan kerugian yang terjadi dalam organisasi (Perdossi)

3. Menjelaskan teknik manipulasi data yang terdapat dalam sistem PIN Perdossi 2013 Medan

\section{TINJAUAN PUSTAKA}

\section{A. Sistem}

Sistem merupakan serangkaian proses atau kegiatan dari elemen yang saling berinteraksi satu dengan yang lain untuk mencapai suatu tujuan (goal). Sistem mempunyai beberapa karakteristik, yaitu: boundary (batasan dalam sistem), environment (lingkungan luar sistem), masukan (input), keluaran (output), komponen sistem, penghubung (interface) dan penyimpanan (storage) (Library Binus, 2012).

Dalam organisasi peran sistem sangat penting untuk mempermudah pengelolaan data. Dewasa ini teknik managing data manual perlahan-lahan mulai ditinggalkan namun begitupun masih ditemukan juga di beberapa organisasi, padahal teknik seperti itu dapat menyebabkan kesalahan data yang disebabkan oleh faktor kesalahan manusia. Oleh karena itu, diperlukan suatu sistem informasi yang mendukung managing data secara efektif dan efisien sehingga data yang terdapat pada organisasi / perusahaan menjadi lebih akurat (Putra, Purnama \& Wardati, 2013).

\section{B. Website}

Pengertian dari website adalah sistem yang dapat menyajikan informasi dalam bentuk teks, gambar, suara, animasi dan video secara dinamis. Registrasi online merupakan salah satu sistem yang dapat dirancang berbasis web. Sistem ini dibuat untuk menggantikan peran dari para petugas pendaftaran yang terdapat dalam suatu organisasi. Alasan registrasi online dirancang berbasis web karena untuk memudahkan kegiatan pendaftaran yang dapat dilakukan dimanapun dan kapanpun menggunakan teknologi internet. Internet merupakan suatu teknologi yang mempunyai kelebihan untuk dapat mengetahui informasi di seluruh dunia tanpa terhalang oleh adanya jarak, waktu dan tempat (Rahayu, Gunadhi \& Partono, 2012).

\section{Managing Data}

Data secara komputerisasi harus diterapkan dalam suatu perusahaan. Salah satu perusahaan yang menggunakan metode komputerisasi menurut literature review ini adalah PD. Azqa yang membangun sistem informasi pengelolaan data transaksi penjualan alat tulis kantor dan jasa photo copy secara kredit. Pengelolaan data transaksi secara kredit selama ini berjalan secara manual. Penerapan sistem manual masih belum dapat memberikan pelayanan yang maksimal, karena muncul berbagai permasalahan, diantaranya adalah kesulitan dalam mencari data transaksi pelanggan dan pengolahan dalam pembuatan laporan bulanan. Oleh karena itu, muncul sebuah ide untuk membangun sistem informasi berbasis komputer yang dapat meminimalkan beberapa permasalahan yang terjadi pada PD. Azqa (Susanto, Supriatna \& Gunadhi, 2012).

\section{METODE PENELITIAN}

\section{A. SDLC Concept}

Dalam merancang sebuah sistem, metodologi memiliki peran penting untuk menganalisa dan mendeteksi cara kerja sistem ketika ingin dibangun dan diteliti. Beberapa metodologi yang bertujuan untuk merancang sebuah sistem mempunyai prosesproses dan tahapan-tahapan berbeda berhubungan dengan alur kerjanya. Metodologi yang diterapakan untuk aplikasi penelitian ini adalah SDLC (System Development Life Cycle) (Searchsoftwarequality, 2008) \& (Webpodia, 2008)

SDLC merupakan sebuah proses yang digunakan untuk mengembangkan sistem informasi yang bertujuan untuk kegiatan-kegiatan yang berhubungan dengan manajemen proyek dengan memberikan penjelasan tahap-tahap yang termasuk dalam proyek pengembangan sistem informasi. 
Pengertian lain dari SDLC dapat berupa suatu model konseptual yang digunakan untuk menggambarkan proses-proses dengan menjelaskan tahap-tahap yang terdapat dalam proyek manajemen (Aulia, R., 2012).

Metodologi SDLC memiliki beberapa model seperti waterfall, RAD (Rapid Application Development), JAD (Joint Application Development) dan fountain and spiral (Mariosalexandrou, 2008). Penelitian ini akan menggunakan enam tahapan yang terdiri project planning, requirements definition, design, development, integration \& test dan installation \& acceptance. Berikut adalah satu dari beberapa tampilan diagram SDLC:

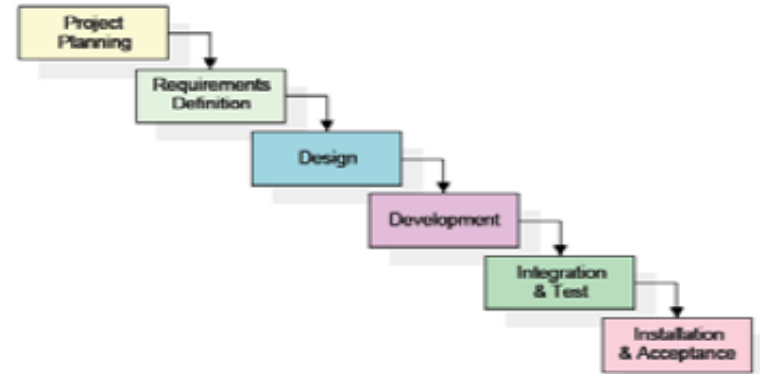

Gbr.1 SDLC Waterfall (adopted from Maheshwari \& Ch. Jain,2012

\section{ANALISIS SISTEM}

Sistem merupakan perancangan sebuah konsep untuk mencapai suatu tujuan utama berdasarkan kebutuhan / spesifikasi yang diharapkan. Dalam merancang sebuah sistem memerlukan keterampilan analisa yang akurat supaya hasil dari suatu perancangan tersebut dapat berkerja sesuai yang diinginkan. Tahap ini merupakan tahap yang sangat kritis dan penting karena apabila terjadi kesalahan dalam menganalisa sistem maka akan menimbulkan kesalahan-kesalahan lain pada langkah-langkah berikutnya. Analisa sistem umumnya dilakukan dengan menggunakan diagram yang dikenal sebagai flowchart, berisikan simbol-simbol tertentu yang diterapkan untuk menggambarkan proses atau alur kerja dari sebuah sistem. Penggunaan diagram dalam mendeskripsikan proses sistem dianggap lebih memudahkan dalam memahami bagaimana cara kerja suatu sistem.

\section{A. Registrasi Online}

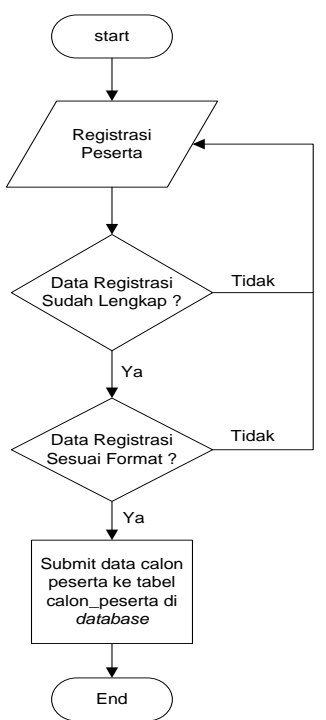

Gbr. 2 Flowchart Registrasi Online Calon Peserta PIN 2013

Berdasarkan gambar 2 di atas, sistem pendaftaran calon peserta PIN 2013 Medan dimulai dengan membuka halaman pendaftaran di website PIN 2013. Setelah itu, calon peserta diminta untuk memasukkan data pada halaman pendaftaran online. Terdapat dua kondisi, yaitu: proses tidak akan berlanjut jika data pada form pendaftaran tidak dilengkapi dan terdapat ketidaksesuaian format terhadap data yang dimasukkan, seperti: format input e-mail, format input hanya data numerik (data angka), dan lain-lain. Jika kedua kondisi tersebut benar, maka sistem berlanjut untuk memproses data yang telah di-input-kan disimpan ke tabel "calon peserta" dalam database.

\section{B. Pembayaran via ATM}

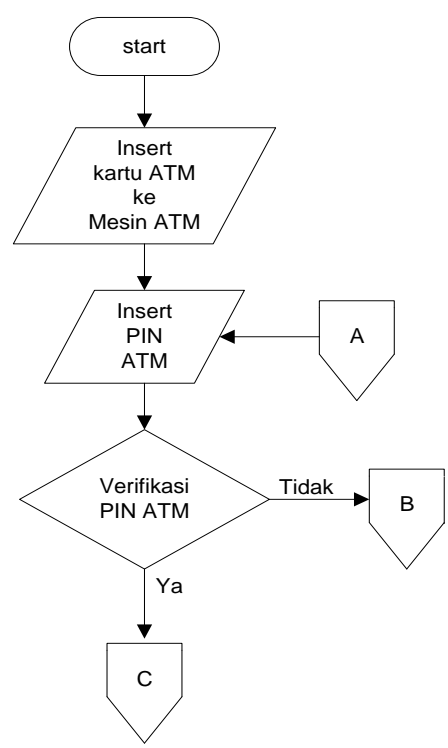




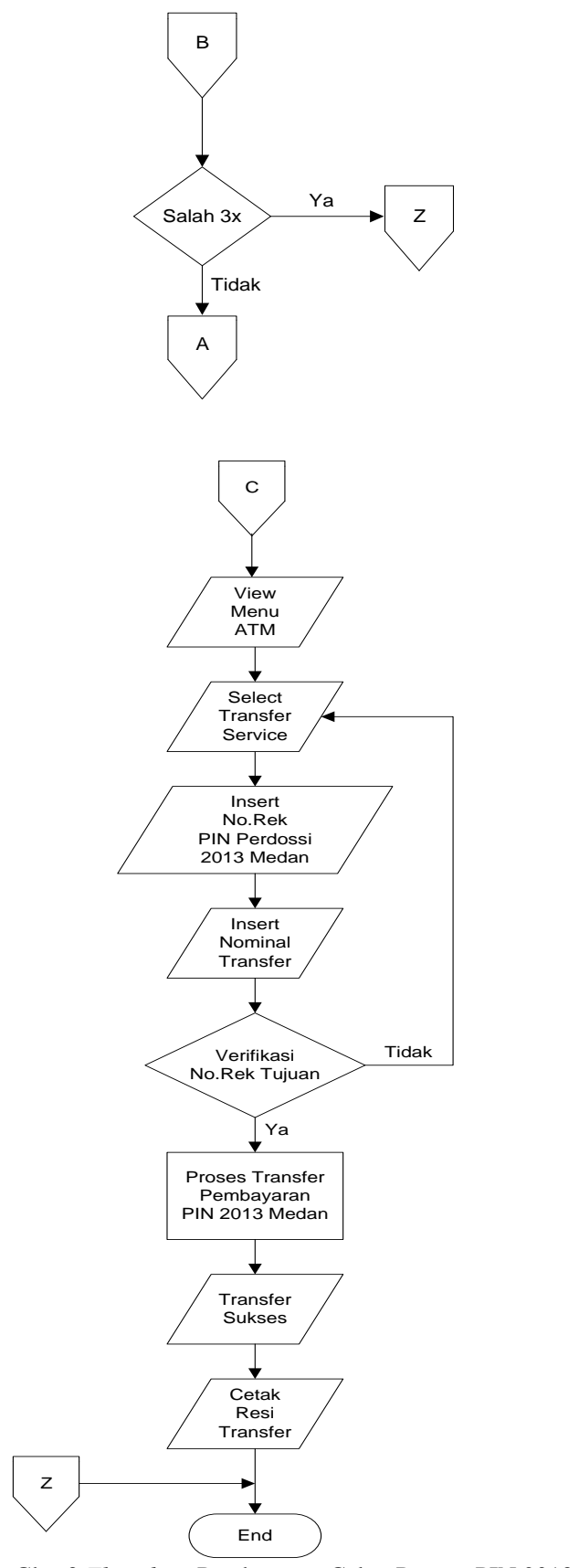

Gbr. 3 Flowchart Pembayaran Calon Peserta PIN 2013

Berdasarkan gambar 3 di atas, pembayaran untuk calon peserta yang telah registrasi dilakukan menggunakan ATM (automatic teller machine). Seperti biasa, calon peserta memasukkan kartu ATM dan setelah itu sistem meminta untuk memasukkan PIN kartu ATM-nya. Disini kesalahan hanya dapat terjadi sebanyak tiga kalii. Jika kesalahan memasukkan PIN lebih dari tiga kali maka sistem langsung memblokir kartu ATM. Namun, jika PIN benar maka sistem menampilkan halaman utama sistem ATM. Calon peserta diminta untuk mentrasferkan dana sesuai yang tercetak pada sistem PIN 2013. Setelah menu transfer dipilih, maka akan keluar tampilan untuk memasukkan nomor rekening panitia PIN 2013. Setelah itu, maka calon peserta diminta untuk memasukkan nominal / jumlah transfernya. Selanjutnya, sistem ATM akan menampilkan data nomor rekening tujuan. Disini, calon peserta diharuskan teliti, karena jika data yang tampil berbeda dengan nomor rekening tujuan (PIN 2013) maka transfer dana dapat dibatalkan. Namun, jika benar, maka proses transfer untuk pembayaran dapat dilanjutkan (diproses). Setelah dana ter-transfer maka sistem akan menampilkan pesan transfer dana berhasil dan kemudian langsung mencetak resi transfernya. Resi transfer berfungsi sebagai bukti pembayaran yang sah.

\section{Konfirmasi Pembayaran}

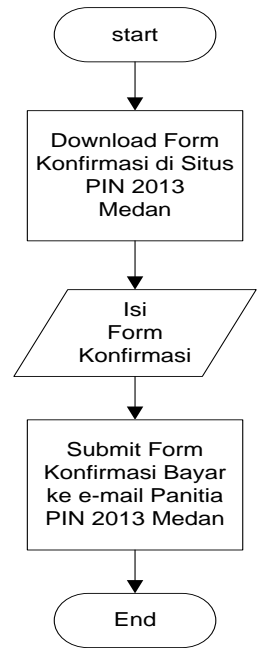

Gbr.4 Flowchart Konfirmasi Pembayaran via E-mail

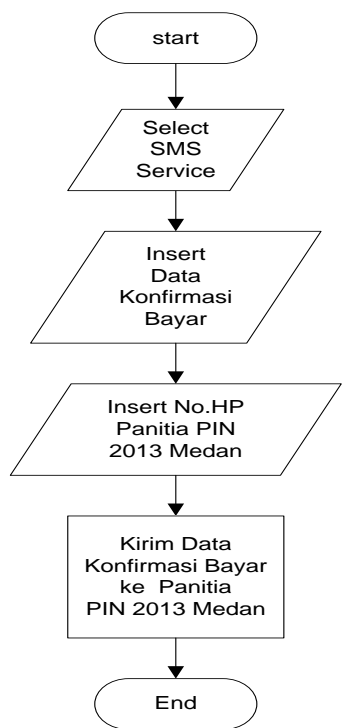

Gbr. 5Flowchart Konfirmasi Pembayaran via SMS

Berdasarkan gambar 4 dan 5, konfirmasi pembayaran yang dilakukan oleh calon peserta PIN 2013 dapat melalui dua cara, yaitu: via e-mail dan via SMS (short messaging service). Konfirmasi pembayaran melalui e-mail dimulai dengan mendownload form konfirmasi di situs resmi PIN 2013 Medan. Selanjutnya, calon peserta melengkapi data yang terdapat dalam form tersebut. Setelah semua data 
terisi, calon peserta dapat mengirimkannya ke e-mail resmi panitia PIN 2013. Selain melalui e-mail, konfirmasi pembayaran dapat dilakukan via SMS. Cara kedua ini dianggap lebih efektif karena setiap orang pasti memiliki handphone dan selalu aktif. Calon peserta dapat memasukkan data yang diperlukan oleh panitia PIN 2013 lewat interface SMS di handphone dan langsung mengirimkannya ke nomor contact person resmi panitia PIN 2013.

\section{Data Pembayaran}

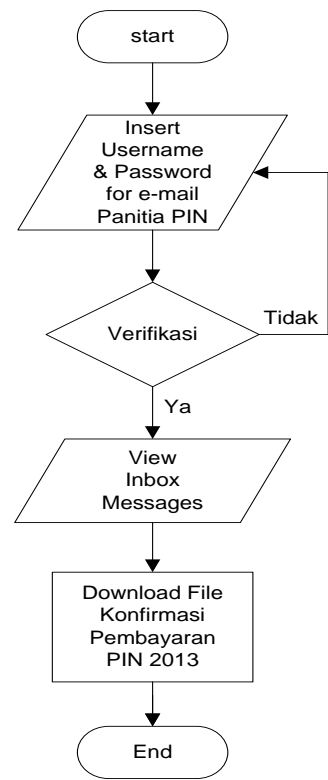

Gbr.6 Flowchart Collect Data Konfirmasi Pembayaran di E-mail

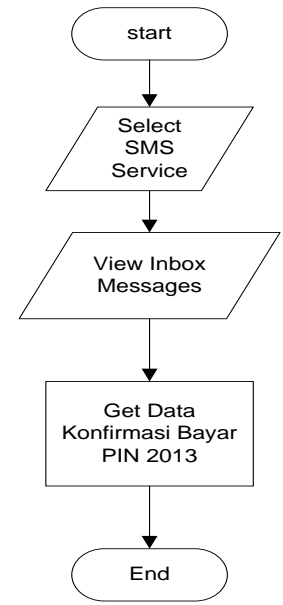

Gbr 7: Flowchart Collect Data Konfirmasi Pembayaran di Inbox SMS

Berdasarkan gambar 6 dan 7, data konfirmasi pembayaran dapat diperoleh melalui dua cara, yaitu: masuk ke e-mail resmi panitia PIN 2013 dan selanjutnya, membuka inbox-nya. Cara lain adalah dengan membuka inbox SMS yang terdapat pada nomor handphone resmi panitia PIN 2013. Setelah data konfirmasi pembayaran calon peserta PIN 2013 telah terkumpul akan di-cross check kembali ke akun rekening Bank resmi yang dimiliki oleh panitia PIN 2013 melalui layanan internet banking.

\section{E. Filterisasi Data}

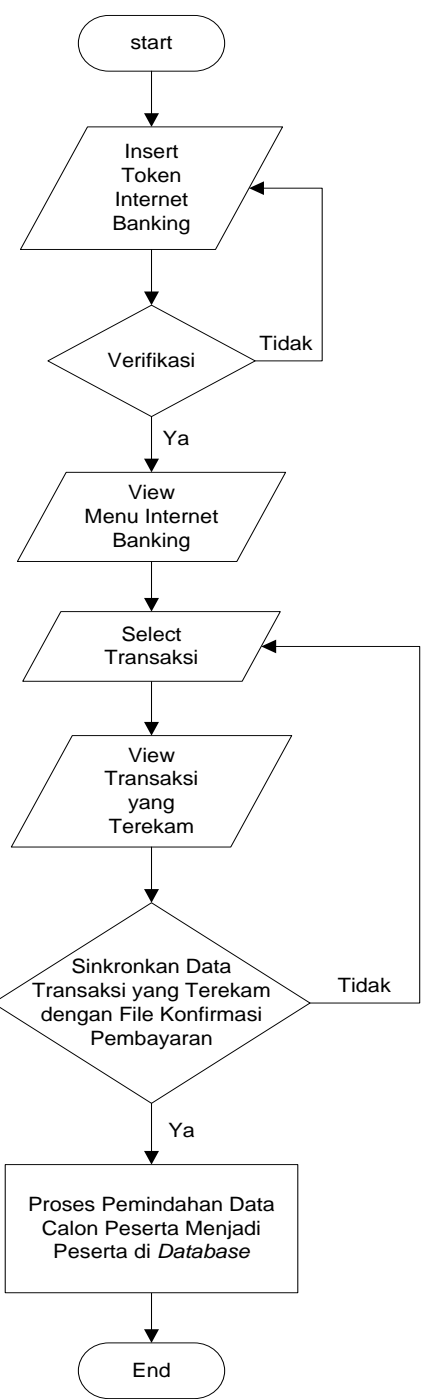

Gbr. 8 Flowchart Filterisasi Data Calon Peserta Menjadi Peserta PIN 2013 Medan

Berdsarkan gambar 8, filterisasi data calon peserta PIN 2013 dapat dilakukan dengan cara mengaktifkan token akun Bank yang digunakan panitia PIN 2013. Hal ini dimaksudkan untuk memudahkan panitia PIN 2013 dalam mengidentifikasi mana calon peserta yang telah melakukan pembayaran dan belum melakukan pembayaran. Seperti biasa, panitia PIN 2013 diminta untuk memasukkan token ke situs rekening Bank yang dimiliki oleh panitia. Setelah verifikasi token benar, maka selanjutnya sistem internet banking menampilkan halaman utama. Dibagian ini panitia PIN 2013 dapat memilih menu transfer untuk melihat tampilan siapa saja calon peserta yang telah bayar (transfer). Dari situ, panitia dapat melakukan sinkronisasi data transaksi dengan data konfirmasi bayar yang telah dikumpulkan. Jika sesuai, maka panitia dapat merubah status calon peserta menjadi 
peserta resmi PIN 2013. Jika tidak,sesuai status calon peserta tetap tidak akan berubah.

\section{KESIMPULAN}

Pemanfaatan teknologi web untuk sistem pendaftaran online PIN 2013 Medan dimaksudkan untuk memudahkan panitia dalam mempromosikan dan merekrut calon peserta PIN 2013 Medan. Selain itu, teknologi web bermanfaat dalam mengelola data calon peserta yang telah masuk ke database dengan mudah dan efektif dalam skala besar. Kemudahan itu terasa karena seluruh data yang masuk ditampung dalam database. Efektif yang dimaksud adalah adanya teknik filterisasi data untuk merubah status calon peserta menjadi peserta resmi PIN 2013, sehingga memudahkan panitia PIN 2013 dalam mengidentifikasi calon peserta yang sudah dan belum melakukan pembayaran. Hal ini dimaksud untuk meminimalkan kerugian materil yang terjadi dalam penyelengaraan PIN 2013 Medan.

\section{REFERENSI}

[1] Aulia, R., (2012). Using an Online Auction System in Open Source. Prosiding. Seminar Nasional Teknologi Informasi \& Komunikasi (Snastikom). 31 Januari - 2 Februari 2012. pp. 7:9-15. Medan

[2] Library Binus. (2012). Teori Sistem Informasi. Retrieved 5 September 2014, from HTTP://library.binus.ac.id/eColls/eThesisdoc/Bab2/2012-1 01037-SIBab2001.pdf

[3] Mayriayanti, R., Purnama, E. B. \& Sukadi. (2013). Aplikasi Pengolahan Jurnal Online pada Sekolah Tinggi Keguruan dan Ilmu Pendidikan (STKIP) PGRI Pacita. Indonesian Journal on Networking and Security. Vol. 2, pg 1-5.

[4] Maheshwari, S. \& Ch. Jain, D. (2012). A Comparative Analysis of Different Types of Models in Software Development Life Cycle. International Journal of Advanced Research in Computer Science and Software Engineering. Vol. 2, pg 285-290.

[5] Mariosalexandrou. (2008). System Development Life Cycle (SDLC). Retrieved 22 January, 2008, from http://www.mariosalexandrou.com/methodologies/ systemsdevelopment-life-cycle.asp.

[6] Putra, S. F., Purnama, E. B. \& Wardati, U. I. (2013). Pembangunan Sistem Informasi Pendaftaran Mahasiswa Baru pada Universitas Terbuka Pacitan. Indonesian Journal on Networking and Security. Vol. 2, pg 1-7.

[7] Perdossi. (2009). Sejarah Ringkas Perdossi. Retrieved 17 April, 2014, from http://www.perdossi.or.id/index.php?uPage=about.about\&sm od=about\&sp=public

[8] Rahayu, B. D., Gunadhi, E. \& Partono. (2012). Perancangan Sistem Informasi Pendaftaran Peserta Didik Baru Berbasis Web Studi Kasus di SMA Negeri 14 Garut. Jurnal Algoritma Sekolah Tinggi Teknologi Garut. Vol. 9, No. 27.

[9] Rawuh, S. (2013). Pengertian SQL Injection dan Contoh Penerapannya. Retrieved 15 April, 2014, from http://padosngelmu.blogspot.com/2013/05/ pengertian-sqlinjection-dan contoh.html

[10] Susanto, D., Supriatna, D. A. \& Gunadhi, E. (2012). Sistem Pengelolaan Data Transaksi Penjualan Alat Tulis Kantor dan Jasa Photo Copy Secara Kredit di PD. AZQA Garut. Jurna Algoritma Sekolah Tinggi Teknologi Garut. Vol. 9, No.26.

[11] SearchSoftwareQuality.com. (2007). Systems Development Life Cycle. Retrieved January 20, 2008, from http://searchsoftwarequality.techtarget.com/ sDefinition/0,,sid92_gci755068,00.html

[12] Webopedia. (2008). SDLC. Retrieved January 20, 2008, from http://www.webopedia.com/TERM/S/ SDLC.html 